\title{
Effect of Visual Stimuli of Indoor Floor Plants upon the Human Responses
}

\section{Yoshihito Kurazumi ${ }^{1}$, Reiko Hashimoto ${ }^{1}$, Agnes Nyilas ${ }^{1}$, Ken Yamashita ${ }^{1}$, Kenta Fukagawa ${ }^{2}$, Emi Kondo3 ${ }^{\text {, Yoshiaki Yamato4, Kunihito Tobita }}{ }^{5}$, Tadahiro Tsuchikawa ${ }^{6}$}

${ }^{1}$ School of Life Studies, Sugiyama Jogakuen University, Nagoya, Japan

${ }^{2}$ Department of Architecture, Kyushu Sangyo University, Fukuoka, Japan

${ }^{3}$ Department of Architecture, Ariake National College of Technology, Omuta, Japan

${ }^{4}$ Department of Architecture and Structural Engineering, Kure National College of Technology, Kure, Japan

${ }^{5}$ School of Humanities and Social Sciences, Osaka Prefecture University, Sakai, Japan

${ }^{6}$ School of Human Science \& Environment, University of Hyogo, Himeji, Japan

Email: *kurazumi@sugiyama-u.ac.jp

How to cite this paper: Kurazumi, Y., Hashimoto, R., Nyilas, A., Yamashita, K. Fukagawa, K., Kondo, E., Yamato, Y., Tobita, K. and Tsuchikawa, T. (2018) Effect of Visual Stimuli of Indoor Floor Plants upon the Human Responses. Health, 10, 928-948. https://doi.org/10.4236/health.2018.107069

Received: June 8, 2018

Accepted: July 14, 2018

Published: July 17, 2018

Copyright $\odot 2018$ by authors and Scientific Research Publishing Inc. This work is licensed under the Creative Commons Attribution-NonCommercial International License (CC BY-NC 4.0). http://creativecommons.org/licenses/by-nc/4.0/

\begin{abstract}
The biophilia hypothesis maintains that animals, which bring benefits for human survival, evolve adaptively to cause a positive emotional response or actions in the human evolution process. When connected in an advantageous environment for survival, effective relaxation and recovery from fatigue are brought about as further physiological functions, rather than a simple stressfree situation. The aim of this study is to clarify the significance of the visual stimulation of indoor floor plants placed in an office floor space. We examined how the green covering factor and gaze distance to indoor floor plants placed on the floor influenced thermal sensation. The thermal environment conditions were set at 3 levels, $25^{\circ} \mathrm{C}, 28^{\circ} \mathrm{C}$, and $31^{\circ} \mathrm{C}$ and the floor and air temperature were homogenous. We set up 8 office floor plans that had no visual stimulation and used indoor floor plants including pachira, monstera, butterfly palm, yucca elephantipes, weeping fig, umbellate, and snake plant for a visual stimulation. The gaze distance, measured from the center of the subject presented with a visual stimulation and the center of the plant, was set at 3 distances: 2.0, 4.5 and $8.0 \mathrm{~m}$. When the conduction-corrected modified effective temperature (ETF) was below $26^{\circ} \mathrm{C}$, the visual stimulation of the indoor floor plants umbellata and monstera, which have a silhouette with low leaf density and rounded leaves, were shown to mitigate the sensation of being cool. The visual stimulation of indoor floor plants with rounded leaves, such as, pachira, monstera, weeping fig, and umbellata, were shown to decrease the feeling of discomfort. For a gaze distance below $4.5 \mathrm{~m}$, a green covering accounting for less than $5 \%$ was shown to be necessary for mitigating the sensa-
\end{abstract}


tion of being cool and improving the feeling of discomfort.

\section{Keywords}

ETF, Green Covering Ratio, Gaze Distance, Indoor Floor Plant, Thermal Response

\section{Introduction}

Fromm [1], a German social psychologist, used the term biophilia to describe the psychological orientation of humans to be attracted to nature and living things. Then the American social psychologist, Wilson [2], defined the biophilia hypothesis as an innate primal connection potentially giving humans a love towards other living things and nature and being part of human nature, which is embedded in us through evolution. Namely, in the evolutionary process, humans are adaptively evolving to produce a positive emotional response and actions regarding living things that are beneficial to survival. The response remains in modern humans [3]. Through the human evolutionary process, we still have a positive feeling towards environments advantageous to survival, and we form the desire to be near to such environs. Conversely, we are disgusted by environments disadvantageous to survival and we desire to avoid them. This desire quickly and automatically developed from the mechanism acquired through the evolutionary process. This idea is based on Zajonc's theory [4] that the affective system comes before cognition.

This biophilia hypothesis has been examined in many experiments. The physician, Selhub, and the natural therapist, Logan, gathered case studies from around the world in "Your Brain on Nature" [5]. The biophilia hypothesis has withstood scrutiny from scientific investigation. For example, the actions we take when walking on a woodland path, when walking on a pavement in a built-up business district, or when finding a stunning vista on a drive are all evidence of the biophilia hypothesis.

Being in contact with these environments that are advantageous to survival is considered to bring about effective relaxation and recovery from fatigue instead of a simple stress-free state. Ulrich [6] claimed that a certain type of nature has a healing effect on humans. Being in contact with environments advantageous to survival, as a further psychological function, is considered to bring about effective relaxation and recovery from fatigue instead of a simple stress-free state. The effect of scenery as seen from a hospital bed has been verified on patients recovering from surgery. Patients who underwent the same surgery at the same hospital were separated into two groups; the first could see trees from their rooms, and the other could only see the walls of buildings. Through the days of hospitalization post-surgery, the number of complaints of pain or discomfort and the amount of analgesics required were compared. In all cases, the group that could 
see the trees were shown to make better recoveries than the other group.

The visual stimulation of natural scenes, such as trees or water, in an urban environment was investigated and shown to affect the thermal perception on higher cognitive processing. Kurazumi et al. [7] used the thermal environment evaluation index, the enhanced conduction-corrected modified effective temperature (ETFe) [8], to show that the human tolerance limit for thermal environment stimulation was higher in a summertime external space than an internal space. Comparing the visual stimulation from natural scenes comprised of trees and greenery to that of artificial scenes comprised of buildings and asphalt, showed that the thermal sensation of a neutral temperature was lower by around $3.5^{\circ} \mathrm{C}$ and effective at subduing thermal perception. Then, comparing natural landscape observation points with other observation points showed that even with an increase in the average skin temperature, a physiological indicator, the reduction of comfort was small. It was also shown that a natural element space, formed of trees and greenery, was more effective at improving comfort than an artificial element space, formed of the concrete and steel, materials usually found in urban landscapes.

By quantitatively understanding the interaction between the visual stimulation of plants in office entrances and the thermal stimulation on the human body, measures that enable the air-conditioning temperature in summer to be set at $28^{\circ} \mathrm{C}$ were investigated. Kurazumi et al. [9], looked at test subjects in a range of environmental conditions that were mildly uncomfortable with a base temperature of $28^{\circ} \mathrm{C}$. For a thermal environment evaluation index, ETF [10] of $28^{\circ} \mathrm{C}$ $29^{\circ} \mathrm{C}$, higher than the mildly uncomfortable range, the effect of visual stimulation as a natural landscape factor due to the greenery of plants in an interior environment was shown to improve thermal sensation. Then, a green covering factor, calculated as the active effect of thermal environment conditions, of up to $70 \%$ was shown to be reasonable from the visual stimulation of depth from 3-dimentional plants. Even in warm air-conditioned spaces that must be endured, the cognitive stimulation of plants and similar greenery were shown to have an effect on the general thermal sensation, and the significance from the positive visual stimulation of greenery in interior spaces was shown. This suggests that the natural landscape factor, or visual stimulation, from greenery can make a comfortable, economic interior environment.

Then, implementing the visual stimulation of the foliage of small indoor floor plants in the office space has been shown to be an effective measure to maintain summertime cooling set at $28^{\circ} \mathrm{C}$. Kurazumi et al. [11] focused on personal space in an office and with the air-conditioning temperature set to $28^{\circ} \mathrm{C}$, they examined subjects in a range of mildly uncomfortable thermal environments. An interior thermal environment evaluation index conduction-corrected modified effective temperature (ETF) [10] of around $27^{\circ} \mathrm{C}-29^{\circ} \mathrm{C}$, was shown to improve thermal sensation resulting from the reports of the visual stimulation of small indoor floor plant foliage. Also, an ETF of around $26^{\circ} \mathrm{C}-29^{\circ} \mathrm{C}$ was shown to 
improve the feeling of comfort resulting from the reports of the visual stimulation of small indoor floor plant foliage. This result shows that no feeling of pressure from a green covering factor of $0.75 \%$ to $4.67 \%$ is remarkable. Small indoor floor plants were included in the natural environment element of personal space and, with the distance between the plant and human being relatively close, it is necessary to ensure that the spread of the crown is not oppressive. Having small indoor floor plants on office desktops as part of the natural element is suggested to make an office space a more energy efficient, amiable environment.

The general thermal sensation of humans is not simply expressed by the thermal equilibrium between the physical environment and the human body. There are discrepancies in thermal sensation in higher cognitive processing from influences between visual and auditory stimulation and the general thermal sensation of the human body. Interior air-conditioning can be mildly too warm or too cool even without having the temperature set at an extreme. While selectively controlling auditory stimulation is difficult, visual stimulation can be selectively controlled. Therefore, if the thermal environment evaluation index can be quantitatively shown from the effect of visual stimulation alleviating mildly uncomfortable thermal environments, we can deduce that air-conditioning running costs will be greatly improved.

Although research has been conducted on various states of greenery on visual stimulation, investigations with indoor floor plants are rare. In office or living spaces, indoor floor plants are utilized as an effective method to relax. Then, through experiments on subjects in mildly uncomfortable thermal environments with a set air-conditioning temperature of $28^{\circ} \mathrm{C}$, a thermal environment evaluation index ETF [10] was used to show that the greenery of indoor floor plants influenced cognitive stimulation. If visual stimulation is shown to effect thermal sensation from higher cognitive processing, then it will be possible to form more energy efficient, environmentally friendly spaces. In order to quantitatively understand the synergy of visual stimulation on discrepancies of thermal sensation on the human body, we investigated measures that were effective in having a summertime cooling temperature of $28^{\circ} \mathrm{C}$.

\section{Experimental design}

\subsection{ETF}

The interior thermal environment evaluation index conduction-corrected modified effective temperature (ETF) was developed by Kurazumi et al. [10]. Then, experiments were conducted that show the relationship between ETF and the effects on the physiology and psychology of the human body, and clarified its effectiveness as an interior thermal environment evaluation index [12]. This ETF can calculate the temperature from individual thermal environment factors; differences in posture, air velocity, long-wavelength thermal radiation, surface contact body temperature, and humidity. 
These five influential environmental factors that are involved in maintaining thermal equilibrium of the human body can express the thermal environment evaluation index with new definitions; $T V F_{h t a}$, the thermal air velocity field combining effects of convection heat transfer due to air velocity; $E R F_{\text {hta }}$, the long-wavelength thermal radiation field combining effects of radiant heat transfer; $E C F_{h t a}$, the effective conduction field combining effects of conductive heat transfer for the contact surface area of the human body; $E H F_{E T F}$, the effective humid field for humidity in ETF. Then, each factor calculates the individual temperature and can be summed to give the air temperature, which allows for the influence of the individual thermal environment factors and general influence on body temperature to be numerically evaluated on a unified axis.

$$
\begin{gathered}
E T F=T_{a}+T V F_{h t a} / h_{f}+E R F_{h t a} / h_{f}+E C F_{h t a} / h_{f}+E H F_{E T F} / h_{f} \\
T V F_{\text {hta }}=\left(h_{o} f c l F c l o f_{\text {conv }}-h_{c} f c l F c l f_{\text {conv }}\right)\left(T_{s}-T_{a}\right) \\
E R F_{\text {hta }}=h_{r} f c l F c l f_{\text {rad }}\left(T_{r}-T_{a}\right) \\
E C F_{\text {hta }}=h_{d} F c l d f_{\text {cond }}\left(T_{f}-T_{a}\right) \\
E H F_{\text {ETF }}=L w h_{c} f c l F p c l\left(p_{a}-0.5 p_{E T F^{*}}\right) \\
h_{f}=h_{o} f_{c l F c l o} f_{\text {conv }}+h_{r} f c l F c l f_{\text {rad }}+h_{d} F_{c l d} f_{\text {cond }}
\end{gathered}
$$

where

ETF: conduction-corrected modified effective temperature $[\mathrm{K}]$;

$T_{a}$ : air temperature $[\mathrm{K}]$;

$T V F_{h t a}:$ convective heat transfer area of the combined thermal velocity field $\left[\mathrm{W} / \mathrm{m}^{2}\right]$;

$E R F_{h t a}$ : radiant heat transfer area combined with the effective radiation field for thermal radiation $\left[\mathrm{W} / \mathrm{m}^{2}\right]$;

$E C F_{h t a}$ : conductive heat transfer area combined effective conduction field $\left[\mathrm{W} / \mathrm{m}^{2}\right]$;

$E H F_{E T F}$ effective humid field at conduction-corrected modified effective temperature $\left[\mathrm{W} / \mathrm{m}^{2}\right]$;

$f c l$ : effective surface area factor of clothing [-];

$f_{\text {conv }}:$ convective heat transfer area factor [-];

$f_{\text {cond: }}$ conductive heat transfer area factor [-];

$f_{r a d}$ : radiant heat transfer area factor [-];

$F c l$ : thermal efficiency factor of clothing in the exposed airflow area [-];

Fcld: thermal efficiency factor of clothing in the heat conduction area [-];

Fclo: thermal efficiency factor of clothing under standard conditions [-];

Fpcl: permeation efficiency factor of clothing [-];

$h_{c}$ : convective heat transfer coefficient $\left[\mathrm{W} / \mathrm{m}^{2} \mathrm{~K}\right]$;

$h_{r}$ : radiant heat transfer coefficient $\left[\mathrm{W} / \mathrm{m}^{2} \mathrm{~K}\right]$;

$h_{d}$ : resultant heat conductance $\left[\mathrm{W} / \mathrm{m}^{2} \mathrm{~K}\right]$;

$h_{\dot{f}}$ sensible heat transfer coefficient $\left[\mathrm{W} / \mathrm{m}^{2} \mathrm{~K}\right]$;

$h_{o}$ : convective heat transfer coefficient under standard conditions $\left[\mathrm{W} / \mathrm{m}^{2} \mathrm{~K}\right]$; 
$L$ : Lewis relation coefficient $[\mathrm{K} / \mathrm{kPa}]$;

$p_{a}$ : water vapor pressure at outdoor air temperature $[\mathrm{kPa}]$;

$p_{\text {ETF }}:$ saturated water vapor pressure at conduction-corrected modified effective temperature $[\mathrm{kPa}]$;

$T_{s}$ : convection-corrected mean skin temperature $[\mathrm{K}]$;

$T_{\dot{f}}$ surface temperature of the contacted material $[\mathrm{K}]$;

$T_{r}$ : mean radiant temperature for long-wave radiation $[\mathrm{K}]$;

W. skin wettedness [-].

\subsection{Experimental Method}

The experiment was similar to that conducted by Kurazumi et al. [9] [11], wherein we investigated the improving effects on the thermal environment through visual stimulation from plants. The experiment was conducted in the laboratory shown in Figure 1. In order to bring the wall and air temperature into equilibrium, thick curtains were installed. The lab was colored white to minimize the effects of visual stimulation. The experiment was run using a screen installed in the lab to display visual stimulation. Thermal environment conditions were set using 3 values for air temperature, $25^{\circ} \mathrm{C}, 28^{\circ} \mathrm{C}$, and $31^{\circ} \mathrm{C}$ where the wall and air temperature were brought into equilibrium. The air velocity (still-air at less than $0.2 \mathrm{~m} / \mathrm{s}$ ) and relative humidity (60\%) were stabilized for each condition.

The subjects were asked to change into white clothing to minimize the effects from visual stimulation in order to verify influences on the human body. The subjects were asked to sit at a desk and quietly work on a task during the experiment.

The subjects were initially asked to sit for over $45 \mathrm{~min}$ in an adjoining room that had settled to a homogeneous wall and air temperature equal to the experimental conditions. The subject then quickly moved to the experiment room and was immersed for over $15 \mathrm{~min}$. Furthermore, the immersion time was over 60 min in order to acclimatize the subject and to cut off the climate history that might have influenced the body temperature. Then, once the set temperature environment conditions and set posture in the immersed conditions were met, the visual stimulation experiment began.

Visual stimulation consisted of a total of 8 images, 7 of which were of $1.0-1.3$ $\mathrm{m}$ tall indoor floor plants on the office floor and one control image consisting of an office floor space with a green covering factor of $0 \%$. The green covering factor is the percentage of the visual stimulation screen taken up by green from the indoor floor plant. The gaze distance is the center of the subject's body and the center of the presented visual stimulation target and was set at 3 distances; $2 \mathrm{~m}$, assumed to be in the vicinity of personal space; $4.5 \mathrm{~m}$, assumed to be corridor space; and $8 \mathrm{~m}$, assumed to be in the vicinity of the entrance. Characteristics of the visual stimulation are as follows: Each visual stimulation was presented for $180 \mathrm{~s}$, then $30 \mathrm{~s}$ later the subject reported their physiological sensations. Visual stimulations were presented in a random order. 


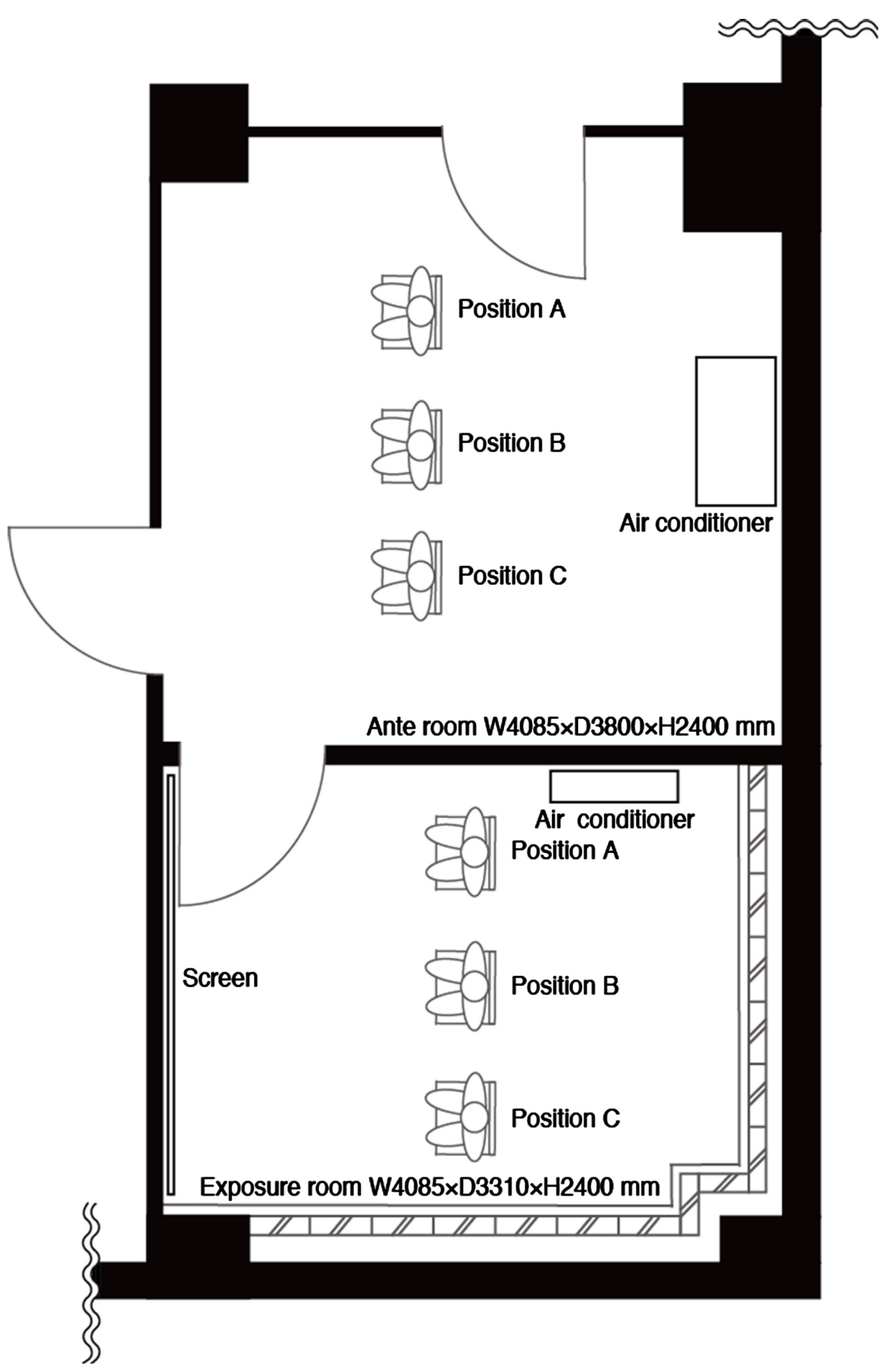

Figure 1. Plan of experimental set up where subjects are exposed to thermal conditions.

\subsection{Visual Stimulation}

Kurazumi et al. [8] showed an improving effect on thermal and comfort sensations in a room when comparing visual stimulation from natural landscape factors comprising greenery and trees or artificial landscape factors comprising buildings and paving. Then, natural landscape factors with a higher solid angle ratio had a stronger effect. Also, Kurazumi et al. [9] showed that for a room it is reasonable that natural landscape factors predict an active effect of thermal en- 
vironment conditions and visual stimulation consisting of bushes and other greenery give a feeling of depth. Then Kurazumi et al. [11] found that it is necessary to pay attention to the sensation of oppression from the spread of the crown when selecting a plant for an office space desktop where the visual stimulation distance between the plant and human is relatively close. In these studies, the visual stimulation in the field of view, or green covering factor, had a high numerical value. However, it is extremely difficult to bring in a large amount of plants into an office space. Additionally, it is essential to maintain corridors. Then indoor floor plants that present a visual stimulation were selected that have a potted height of less than $1.5 \mathrm{~m}$ and vary greatly in the percentage of the field of view covered by greenery.

Images exhibiting visual stimulation assumed the horizontal gaze of a seated office worker whose eyes are at $1.2 \mathrm{~m}$ and that indoor floor plants were $1.0-1.3$ $\mathrm{m}$ from the office floor. The gaze distance is the center of the subject's body and the center of the presented visual stimulation target and was set at 3 distances; 2 $\mathrm{m}$, assumed to be in the vicinity of personal space; $4.5 \mathrm{~m}$, assumed to be corridor space; and $8 \mathrm{~m}$, assumed to be in the vicinity of the entrance. The center of the seated body was taken to be $0.1 \mathrm{~m}$ behind the navel. Also, the center of the target indoor floor plant was taken to be the middle of the pot. Figure 2 shows the indoor floor plants. Table 1 shows the visual stimulation.

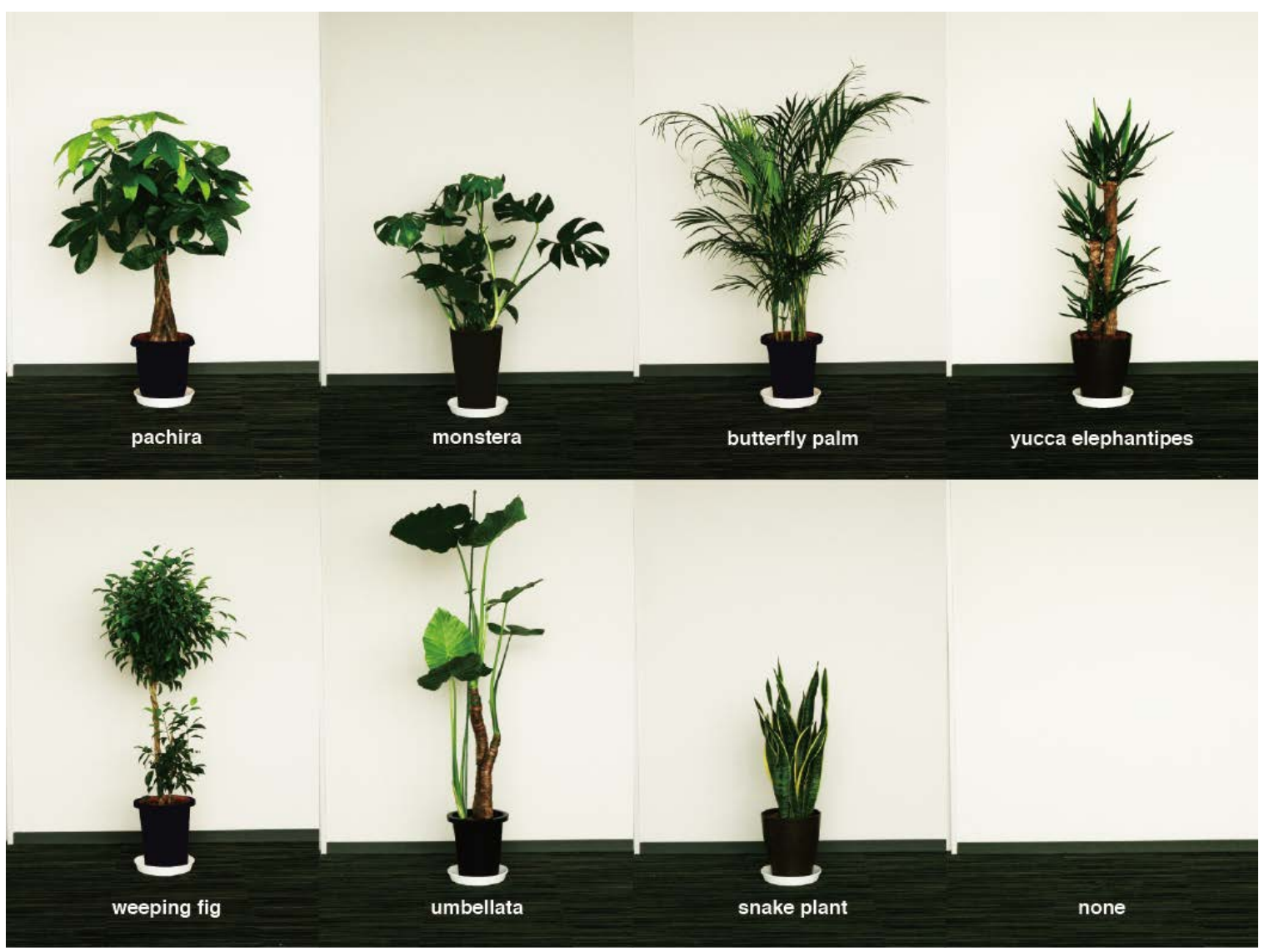

Figure 2. Indoor floor plants as visual stimuli. 
Table 1. Summary of visual stimuli.

\begin{tabular}{cccc}
\hline Visual stimuli scene & $\begin{array}{c}\text { Green factor } \\
\text { Gaze distance } 2.0 \mathrm{~m}\end{array}$ & $\begin{array}{c}\text { Green factor } \\
\text { Gaze distance } 4.5 \mathrm{~m}\end{array}$ & $\begin{array}{c}\text { Green factor } \\
\text { Gaze distance } 8.0 \mathrm{~m}\end{array}$ \\
\hline Pachira & 0.170 & 0.039 & 0.013 \\
Monstera & 0.120 & 0.024 & 0.011 \\
Butterfly palm & 0.170 & 0.048 & 0.017 \\
Yucca elephantipes & 0.062 & 0.019 & 0.005 \\
Weeping fig & 0.110 & 0.027 & 0.008 \\
Umbellata & 0.092 & 0.023 & 0.009 \\
Snake plant & 0.054 & 0.014 & 0.005 \\
None foliage plant & 0.000 & 0.000 & 0.000 \\
\hline
\end{tabular}

Green factor is green covering factor. Green covering factor is defined as the ratio of green surface areas to a picture area.

Visual stimulation were 8 images of an office floor space. 7 images included visual stimulation from the indoor floor plants, which were pachira, monstera, butterfly palm, yucca elephantipes, weeping fig, umbellate, and snake plant, and 1 image of a space with no visual stimulation. Monstera and umbellata were selected for their large leaf surface area. Weeping fig was selected for its small leaf surface area. Pachira, butterfly palm, yucca elephantipes, and snake plant were selected for their characteristic silhouette. They are each used as indoor floor plants for offices.

Pachira has characteristic large palmate leaves. The large leaves for a crown with a dense, thick silhouette. The green covering factor for a gaze distance of 2 , 4.5 , and $8 \mathrm{~m}$ was $17.0 \%, 3.9 \%$, and $1.3 \%$, respectively.

Monstera has large characteristic leaves with deeper incisions than pachira. The crown has a horizontal spreading silhouette. The green covering factor for a gaze distance of $2,4.5$, and $8 \mathrm{~m}$ was $12.0 \%, 2.4 \%$, and $1.1 \%$, respectively.

Butterfly palm has long, thin characteristic leaves. The silhouette of the leaves resembles a dense fountain. The green covering factor for a gaze distance of 2 , 4.5 , and $8 \mathrm{~m}$ was $17.0 \%, 4.8 \%$, and $1.7 \%$, respectively.

Yucca elephantipes has characteristic ensiform leaves. The silhouette of the leaves resembles a dense cylinder. The green covering factor for a gaze distance of $2,4.5$, and $8 \mathrm{~m}$ was $6.2 \%, 1.9 \%$, and $0.5 \%$, respectively.

Weeping fig has characteristic leaves with a small surface area. The crown has a rounded silhouette resembling many dense balloons. The green covering factor for a gaze distance of $2,4.5$, and $8 \mathrm{~m}$ was $11.0,2.7$, and $1.4 \%$, respectively.

Umbellata has characteristic large chordate leaves. The crown has few leaves and has a smart silhouette resembling raised umbrellas. The green covering factor for a gaze distance of $2,4.5$, and $8 \mathrm{~m}$ was $9.2 \%, 2.3 \%$, and $0.9 \%$, respectively.

Snake plant has characteristic long, thin ensiform leaves. The silhouette of the leaves resembles a dense cylinder. The green covering factor for a gaze distance of $2,4.5$, and $8 \mathrm{~m}$ was $5.4 \%, 1.4 \%$, and $0.5 \%$, respectively. 
Furthermore, for an eye height of $1.2 \mathrm{~m}$ for the subject, the solid angle ratio of visual stimulation, when the line of sight is taken to be the center of the presentation screen, are 0.09, 0.10, and 0.09 for Positions A, B, and C, respectively. The variation of solid angle ratio of visual stimulation from the observer position is 0.01 , which is not considered significant.

\subsection{Subjects}

Nine healthy adolescent female university students were used as the test subjects. Their characteristics are shown in Table 2. The nine females were $155.0 \pm 4.3 \mathrm{~cm}$ tall and weighed $49.0 \pm 6.7 \mathrm{~kg}$. All of the test subjects were of standard physique.

Following the Helsinki Declaration [13], all participants were fully aware of the content of the experiment and gave their consent to take part.

Experiments with subjects measuring physiological and psychological quantities as human body reactions are rarely performed using a large number of subjects. In addition, it is difficult to perform experiments assuming a statistical population. Therefore, although there are few subjects in this study, they are considered meaningful as new data.

It is rare to perform a subjective experiment that measures physiological and psycho-logical quantities according to the response of the human body using a large number of subjects. It is difficult to perform an experiment that is hypothesized on a statistical popula-tion. Accordingly, as only a small number of subjects was used in this study, the new data are a significant addition to the literature.

\subsection{Measurements}

Air temperature, humidity, air velocity, and wall surface temperature were measured as thermal environment conditions. Air temperature and humidity were measured using a miniature temperature and humidity data logger (ESPEC

Table 2. Physical characteristics of subjects.

\begin{tabular}{cccccccc}
\hline Subject & Sex & Age & Height $[\mathrm{cm}]$ & Weight $[\mathrm{kg}]$ & B-area $\left[\mathrm{m}^{2}\right]$ & Rohrer Index & Native place \\
\hline NH & Female & 21 & 151.8 & 57.2 & 1.53 & 163.7 & Aichi \\
YY & Female & 21 & 150.5 & 44.6 & 1.39 & 130.9 & Aichi \\
YR & Female & 21 & 149.3 & 44.2 & 1.37 & 133.1 & Fukui \\
HN & Female & 21 & 158.0 & 63.8 & 1.64 & 161.8 & Aichi \\
GR & Female & 21 & 151.9 & 44.1 & 1.39 & 125.8 & Aichi \\
YM & Female & 21 & 155.5 & 46.4 & 1.44 & 123.5 & Osaka \\
KN & Female & 22 & 156.0 & 44.6 & 1.42 & 117.5 & Aichi \\
YK & Female & 21 & 160.2 & 46.0 & 1.47 & 111.8 & Aichi \\
TK & Female & 21 & 162.6 & 50.1 & 1.53 & 116.7 & Aichi \\
\hline
\end{tabular}

B-area is the calculated body surface area by Kurazumi's formula [17]. S $=100.315 \mathrm{~W} 0.383 \mathrm{H} 0.693 \times 10^{-4}$ (Kurazumi et al., 1994). S: Body surface area $\left[\mathrm{m}^{2}\right]$, W: Weight $[\mathrm{kg}], \mathrm{H}$ : Height $[\mathrm{cm}]$. Native place is life region from birth to 2.5 years old time. 
MIC: RS-13, temperature range; $0^{\circ} \mathrm{C}-50^{\circ} \mathrm{C}$, precision; $0.3^{\circ} \mathrm{C}$, humidity range; $10 \%-95 \%$, precision; $5 \%$ ) set at $0.6 \mathrm{~m}$ above the floor. Air velocity was measured using a hot-ball, omnidirectional anemometer (Kanomax Japan: 6533, range: $0.05-5.00 \mathrm{~m} / \mathrm{s}$, precision; $2 \%$ ) set at $0.6 \mathrm{~m}$ above the floor. The surface temperature of each surface forming the room was measured using a $0.2 \mathrm{~mm} \varphi \mathrm{T}$ thermocouple.

The solid angle of visual stimulation was measured photographically using an equal solid angle fisheye lens (Olympus: Fisheye Zuiko $8 \mathrm{~mm} \mathrm{f/2.8)}$ ) and a $35 \mathrm{~mm}$ digital single lens reflex camera (Canon: EOS 5D) to take a projected fish eye picture of the line of sight of the center of the presented image for the seated test subject eye height of $1.2 \mathrm{~m}$ above the floor.

A skin temperature thermistor (Nikkiso thermo-N542R data logger, range; $-50^{\circ} \mathrm{C}-230^{\circ} \mathrm{C}$, graduation; $0.01^{\circ} \mathrm{C}$, and Nikkiso thermos-body surface probe: ITP8391) was used to measure the physiological state of the body. Skin temperature was measured at 8 points: head, trunk, arm, hand, thigh, calf, foot, and sole.

Subjects wore light clothing comprising a T-shirt, shorts, panties, and a bra-top. Clothing is shown in Table 3. Since undergarments were difficult to match, the subjects used their own. The clo-value was calculated from the clothing amount equation of Hanada et al. [14]. The subject's average clothing thermal resistance was 0.32 clo.

This study measured the psychological response 30s after visual stimulation from a discrete graded scale for human psychological conditions; thermal sensation (7 ranks), coolness sensation (7 ranks), and comfort (7 ranks). Thermal sensation was graded from "cold" to "hot" and comfort from "uncomfortable" to "comfortable". The extreme values for "cold" and "uncomfortable" were -3 , and "hot" and "comfortable" were 3, with intermediate values graded equally.

ETF [10] is a thermal environment evaluation index based on thermal equilibrium between the environment and the human body. Then, the calculation of average skin temperature, using the calculated thermal equilibrium of the body, used a weighting factor that considers the convection heat transfer area [15]. The average skin temperature calculated using the body's physiological response uses a weighting factor that considers thermal conductivity [16].

The body surface area was calculated using the equation by Kurazumi et al. [17]. The convective heat transfer area factor and radiant heat transfer area factor of the body used the value for conduction heat transfer area ratio given by

Table 3. Clothing ensembles of subjects.

\begin{tabular}{lccc}
\hline Subject & Description & Material [\%] & Weight [g] \\
\hline Female & Panties & - & $19-29$ \\
& Bra top short-sleeved shirt & Cotton & $151-246$ \\
& Short pants & Cotton 98\%, PU 2\% & $182-200$ \\
\hline
\end{tabular}

PU is polyurethane. 
Kurazumi et al. [18]. The angle factor of the body in a seated position used the value given by Tsuchikawa et al. [19]. The radiant heat transfer area factor and convective heat transfer coefficient used the value given by Kurazumi et al. [20]. Body emissivity used a value of 0.98 , calculated by Hendler et al. [21] from the skin reflectance of EM radiation longer than $3 \mu \mathrm{m}$. The body's evaporative heat loss can be calculated from the water thermal radiation multiplied by the weight loss from latent heat of evaporation. However, since the experiment only measured body weight immediately before and immediately after being immersed in the experimental environmental conditions, the body's evaporative heat loss due to each visual stimulation could not be measured. Then, a calculated value for skin wettedness was used from the behavioral thermoregulation model by $\mathrm{Ku}$ razumi et al. [22]. The thermal environment evaluation index ETF, theoretically suggested and investigated by Kurazumi et al. [10] [12], was calculated from the thermal environment factor measurements and the body's skin temperature and clothing amount.

Values explaining thermal sensation, such as thermal sensation from direct environmental stimulation including air temperature, humidity, air velocity, long-wavelength thermal radiation, and temperature of surfaces in contact with the body have a large effect on physiological and psychological responses of the body. However, thermal sensation from indirect environmental stimulation including visual stimulation, are not considered to contribute significantly to physiological and psychological responses of the body. Especially, indirect environmental stimulation, including visual stimulation, is expressed as a difference in general thermal sensation in higher cognitive processing. Then, interior air-conditioning does not need to be set at an extreme temperature, which allows for a mildly uncomfortable thermal environment that is slightly warm or cold. Due to the large disturbances and variability in the psychological response of the body in an interior environment in this study, a $10 \%$ probability of significance was placed on the relative standard of explanatory values used to derive the results from regressive analysis of high applicability. JMP13.2.0 (SAS Institute Japan) was used for the statistical analysis.

\section{Results}

The average resulting air temperature was $0.2^{\circ} \mathrm{C}$ below the set value, however the variation was within $\pm 0.6^{\circ} \mathrm{C}$. The average resulting wall and ceiling surface temperatures were $0.4^{\circ} \mathrm{C}$ above the set value, however the variation was within $\pm 0.2^{\circ} \mathrm{C}$. The average resulting floor temperature was $0.3^{\circ} \mathrm{C}$ below the set value, however the variation was within $\pm 0.3^{\circ} \mathrm{C}$. The average resulting relative humidity was $8.5 \%$ above the set average, however the variation was within $\pm 3.9 \%$. Variations in air temperature were slightly increased, however the standard deviation was within $\pm 0.6^{\circ} \mathrm{C}$. Previous air velocity measurements were below $0.2 \mathrm{~m} / \mathrm{s}$. It was considered to be almost steady for all experiments.

As stated above, stimulation in the physical environment directly related to 
thermal sensation, such as thermal sensation from direct environmental stimulation, including air temperature, humidity, air velocity, long-wavelength thermal radiation, and temperature of surfaces in contact with the body have a large effect on physiological and psychological responses of the body. Then, further considerations should examine the influence of those stimulations on the body using thermal environment evaluation index, ETF [10], based on the thermal equilibrium between the human body and the environment.

\section{Discussion}

\subsection{ETF and Mean Skin Temperature}

Figure 3 shows the relationship between ETF and mean skin temperature. This shows a trend that as ETF increases, so too does the average skin temperature. By focusing on nearly equal ETF increments, for each visual stimulation, the ETF had a fairly large distribution of about $26^{\circ} \mathrm{C}-28^{\circ} \mathrm{C}$.

Focusing on the regressive curve for each visual stimulation, the differences in the average skin temperature due to visual stimulation are regarded as minor measurement errors and did not show any significant difference.

Testing the parallelism of regression lines gave a result of $\mathrm{p}>0.10(\mathrm{~F}=0.05, \mathrm{p}$ $=1.00)$, showing no significant difference. Testing the homogeneity of regression lines gave a result of $\mathrm{p}>0.10(\mathrm{~F}=0.07, \mathrm{p}=1.00)$, showing no significant difference. The Steel test for multiple comparisons gave a result of $p>0.10$ between conditions with no visual stimulation from indoor floor plants and for each condition with indoor floor plants, showing no significant difference due to visual stimulation. Therefore, within the range of ETF results from this study, indoor floor plants as visual stimulation are not thought to have a large effect on

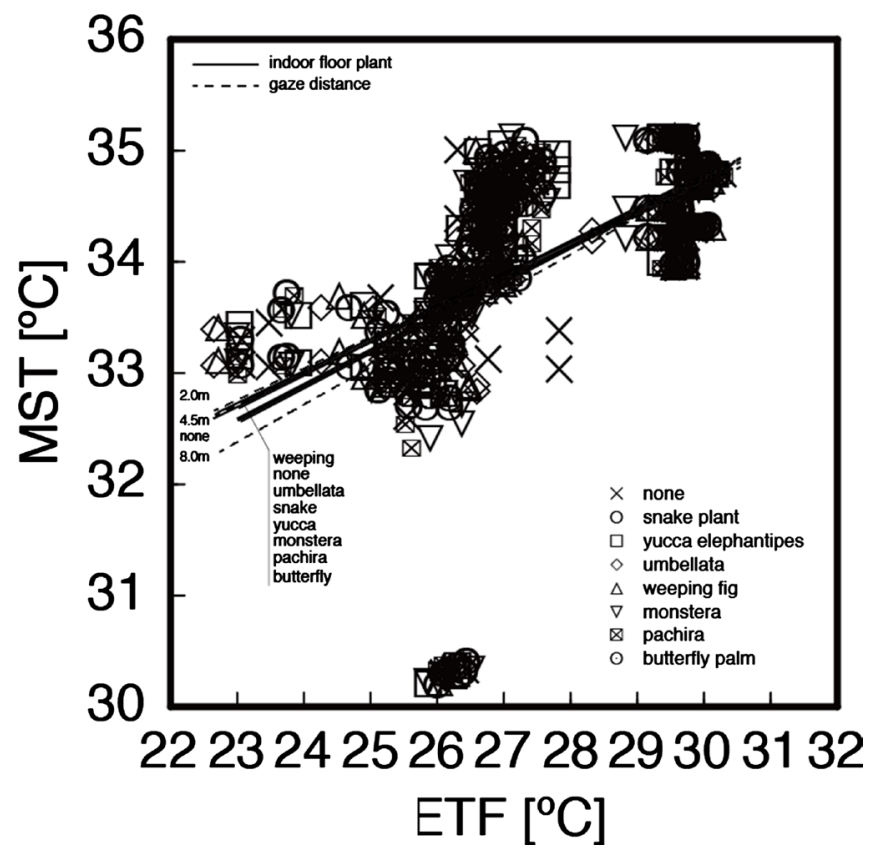

Figure 3. Relationship between ETF and mean skin temperature. 
average skin temperature, similar to the observations by Kurazumi et al. [9] [11].

Focusing on the regressive curve for each gaze distance, the differences in the average skin temperature due to gaze distance showed a slightly lower trend for $8 \mathrm{~m}$, others are regarded as minor measurement errors and did not show any significant difference.

Testing the parallelism of regression lines gave a result of $\mathrm{p}>0.10(\mathrm{~F}=0.82, \mathrm{p}$ $=0.44)$, showing no significant difference. Testing the homogeneity of regression lines gave a result of $\mathrm{p}>0.10(\mathrm{~F}=0.65, \mathrm{p}=0.52)$, showing no significant difference. The Steel test for multiple comparisons gave a result of $p>0.10$ between each gaze distance, showing no significant difference due to visual stimulation. Therefore, within the range of ETF results from this study, the gaze distance of indoor floor plants as visual stimulation is not thought to have a large effect on average skin temperature.

\subsection{ETF and Thermal Sensation}

Figure 4 shows the relationship between ETF and thermal sensation. Thermal sensation has a large distribution. Therefore, this thermal sensation distribution verifies a trend that as ETF increases, thermal sensation increases correspondingly to the hot side. There is a large overlap of thermal sensation since it is on a discrete graded scale, however in comparison with the study by Kurazumi et al. [11], on visual stimulation from small indoor floor plants on office desktops, for a slightly cool set temperature of $25^{\circ} \mathrm{C}$, an effective improvement to thermal sensation was verified.

Focusing on the regressive curve for each visual stimulation, no large difference in thermal sensation due to visual stimulation was found for an ETF higher than about $27^{\circ} \mathrm{C}$. However, when ETF was less than about $26^{\circ} \mathrm{C}$, conditions with

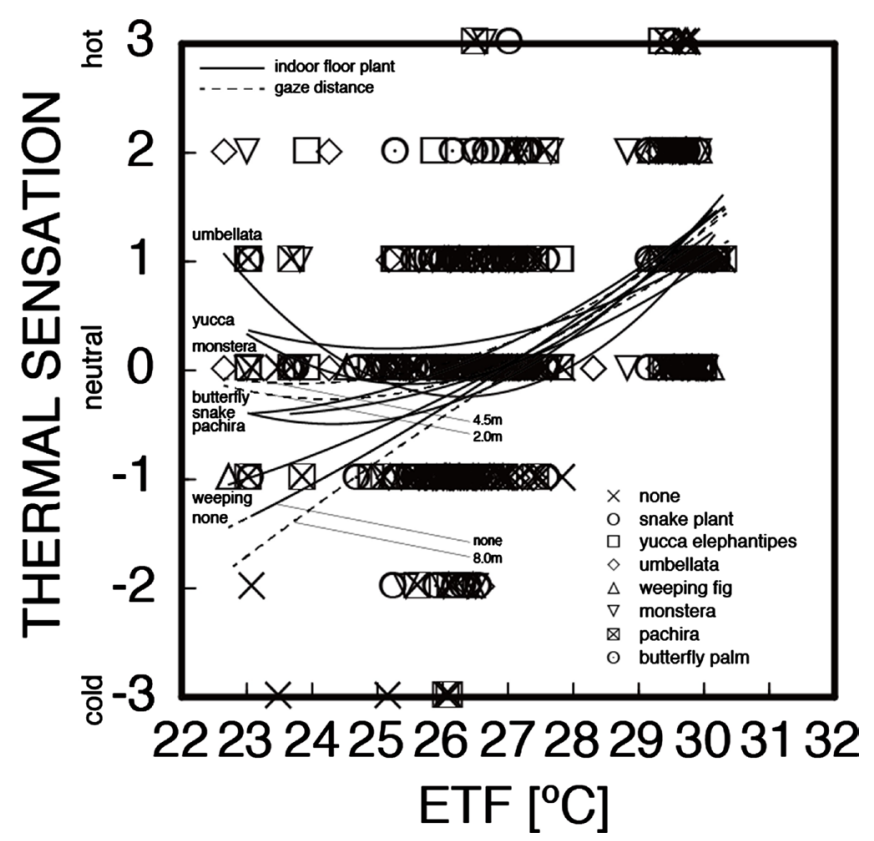

Figure 4. Relationship between ETF and thermal sensation. 
indoor floor plants as visual stimulation showed a trend of alleviating the cold sensation, compared to conditions without visual stimulation.

The alleviation effect of the cold sensation by umbellata and monstera was significant for temperature ranges when ETF was lower than about $26^{\circ} \mathrm{C}$. Each plant has fewer leaves, giving a smaller silhouette. However, plants with denser silhouettes, namely weeping fig, pachira, butterfly palm, and snake plant had lower alleviation effects for the cold sensation. Also, each condition without visual stimulation from indoor floor plants on the floor showed a trend of alleviating the cold sensation, compared to conditions without visual stimulation.

The visual stimulation from plants was better in physical thermal environments that were slightly warm and uncomfortable, also Kurazumi et al. [9] [11] studied the possibility of improvement by visual stimulation from plants in physical thermal environments that were slightly cool and uncomfortable. In previous studies, physical thermal environments that were slightly warm and uncomfortable, visual stimulation from plants was shown to be effective at alleviating the sensation of warmth. However, visual stimulation from plants in physical thermal environments that were slightly cool and uncomfortable was not shown to be effective at alleviating the sensation of cold. These studies showed the alleviation effects of thermal sensation by classifying the green covering factor of visual stimulation, however the indoor floor plants used in the studies resulted in no clear difference in the human response to the green covering factor.

Fukagawa et al. [23] and Kurazumi et al. [9] [11] found that scenery with tall plants with a high green covering factor strengthened the sense of closeness, and spaces with a sense of openness contributed to improving thermal sensation for mildly uncomfortable thermal environments. Studies by Fukagawa et al. [23] and Kurazumi et al. [9] had distant visual stimulation, and target environmental stimulation conditions with the natural environment elements occupying a large solid angle in the field of view. However, studies by Kurazumi et al. [11] looked at environmental stimulation that caused a sense of oppression, using close up visual stimulation placed in the personal space of an office desktop.

These studies had the tendency to overestimate the awareness distance of space for near target objects, and underestimated it for far objects. The visual stimulation and gaze distance for the target object in this study are considered to be recognizable as not matching the feeling of distance. Then, separating the green covering factor from the effect on thermal sensation of the visual stimulation is considered to be one element of difficulty.

An equality test between conditions without visual stimulation from indoor floor plants and conditions with indoor floor plants was conducted using a nonlinear quadratic regression model. The intercept, slope and quadratic coefficients between each condition and the condition without visual stimulation from indoor floor plants were each $\mathrm{p}>0.10$ and showed no significant difference. The effect of visual stimulation of indoor floor plants in this study are thought to be 
influenced by awareness distance and partiality for the indoor floor plants. The variation in general thermal sensation due to higher cognitive processing surmised from the range of results in this study is considered that it is possible to organically improve the thermal sensation in an inorganic office work space by placing the indoor floor plants, umbellata or monstera, which have a low leaf density silhouette, on the office floor.

Focusing on the regressive curve for each gaze distance, no large difference in thermal sensation due to gaze distance was found for an ETF higher than about $27^{\circ} \mathrm{C}$. However, when ETF was less than about $26^{\circ} \mathrm{C}$, a difference in thermal sensation was shown to depend on the presented state of gaze distance. For a gaze distance of $2 \mathrm{~m}$ and $4.5 \mathrm{~m}$, a tendency to alleviate the sensation of cold was verified for conditions presenting visual stimulation from indoor floor plants compared to conditions without visual stimulation. However, for a gaze distance of $8 \mathrm{~m}$, there was no significant difference from conditions without visual stimulation from indoor floor plants.

In this study, a gaze distance of $8 \mathrm{~m}$ for visual stimulation is considered to be judged as a distant awareness distance. Therefore, a gaze distance of $8 \mathrm{~m}$ that has an extremely small green covering factor is not considered to be significantly different from the condition without visual stimulation from indoor floor plants. However, gaze distances of $2 \mathrm{~m}$ and $4.5 \mathrm{~m}$ are judged to be similar to close awareness distances and visual stimulation from indoor floor plants was confirmed to alleviate the cool sensation compared to conditions without indoor floor plants. Then, compared to $2 \mathrm{~m}$, a gaze distance of $4.5 \mathrm{~m}$ showed improved results of thermal sensation. This is thought to be due to tall plants with a high green covering factor strengthening the closed sensation, as pointed out by $\mathrm{Fu}$ kagawa et al. [23] and Kurazumi et al. [9] [11].

An equality test between conditions without visual stimulation from indoor floor plants and gaze distance was conducted using a nonlinear quadratic regression model. The intercept, slope, and quadratic coefficients between a gaze distance of $2 \mathrm{~m}$ and $4.5 \mathrm{~m}$ and the condition without visual stimulation from indoor floor plants were each $\mathrm{p}<0.10$ and showed a significant difference. The effects of visual stimulation of indoor floor plants in this study are thought to be influenced by awareness distance and partiality for the indoor floor plants. The variation in general thermal sensation due to higher cognitive processing surmised from the range of results in this study considers that it is possible to organically improve the thermal sensation in an inorganic office work space by placing indoor floor plants on the office floor.

\subsection{ETF and Thermal Comfort}

Figure 5 shows the relationship between ETF and comfort. Comfort has a large distribution. There is a large overlap of comfort since it is on a discrete graded scale, yet an ETF of $26^{\circ} \mathrm{C}-27^{\circ} \mathrm{C}$ showed a trend as being the most comfortable thermal environment. 


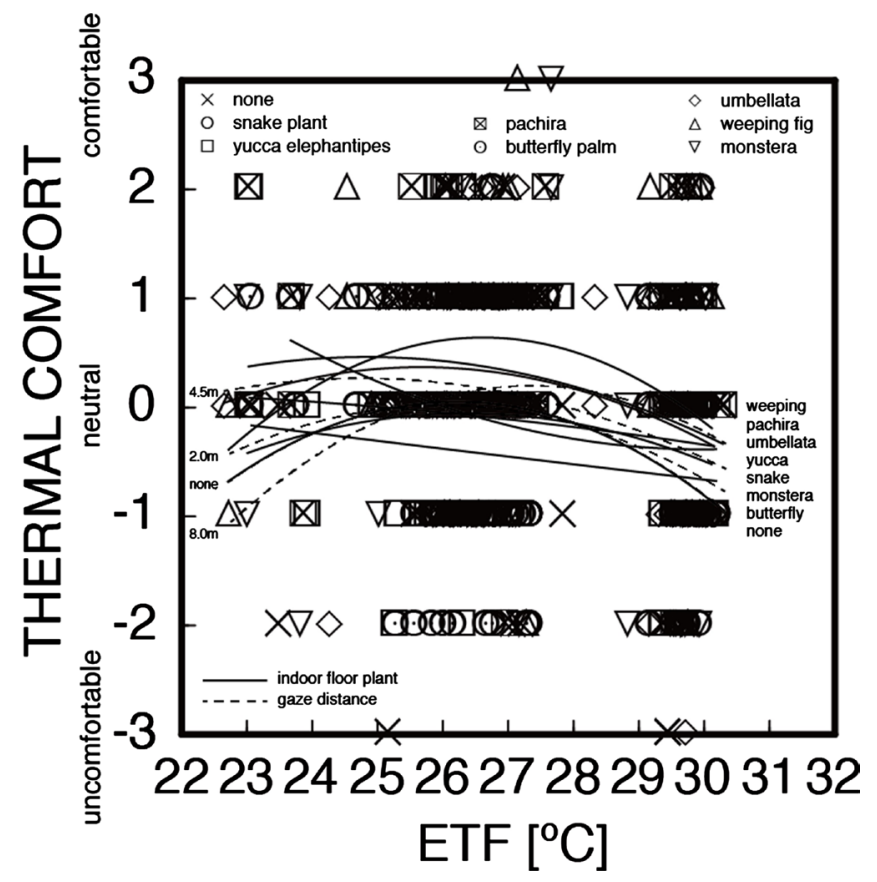

Figure 5. Relationship between ETF and thermal comfort.

Focusing on the regression curves for each visual stimulation, thermal environments with an ETF of $29^{\circ} \mathrm{C}-30^{\circ} \mathrm{C}$ and an ETF of $23^{\circ} \mathrm{C}-24^{\circ} \mathrm{C}$, were verified to improve the feeling of discomfort in conditions displaying visual stimulation from indoor floor plants on the floor, compared to conditions without visual stimulation. The quadratic coefficients for the butterfly palm, snake plant, and yucca elephantipes which have dense foliage with long thin leaves differed from other visual stimulation conditions. Other visual stimulation showed a discernable peak in comfort. However, the results for butterfly palm, yucca elephantipes, and snake plant showed no discernable peak. Conditions displaying pachira, monstera, weeping fig, and umbellata were shown to improve the feeling of discomfort, compared to conditions without visual stimulation from indoor floor plants.

An equality test between conditions without visual stimulation from indoor floor plants and conditions with indoor floor plants was conducted using a nonlinear quadratic regression model. The intercept, slope, and quadratic coefficients between butterfly palm, yucca elephantipes, and snake plant and the condition without visual stimulation from indoor floor plants were each $\mathrm{p}<0.10$ and showed a significant difference. Preference for the indoor floor plants is considered to have an effect, however the dense foliage of butterfly palm, yucca elephantipes, and snake plant are considered to have a difference in evaluation of comfort.

Pachira, monstera, weeping fig, and umbellata that have rounded leaves showed no significant difference with conditions without visual stimulation from indoor floor plants. However, they are thought to show improvement of comfort. 
Focusing on the regressive curve for each gaze distance, for thermal environments with an ETF of $29^{\circ} \mathrm{C}-30^{\circ} \mathrm{C}$ and of $23^{\circ} \mathrm{C}-24^{\circ} \mathrm{C}$, conditions with visual stimulation from indoor floor plants showed an improvement in the feeling of discomfort compared to the situation with no visual stimulation. Especially, the thermal environment with an ETF of $23^{\circ} \mathrm{C}-24^{\circ} \mathrm{C}$ and a gaze distance of $4.5 \mathrm{~m}$ showed significant improvement to the feeling of discomfort.

As stated in the relationship between ETF and thermal sensation regarding gaze distance, in this study, a gaze distance of $8 \mathrm{~m}$ is considered to be determined as a far awareness distance. Kurazumi et al. [9] found low visual stimulation due to a green covering factor of $20 \%-40 \%$ as seen from a window. Therefore, for a gaze distance of $8 \mathrm{~m}$, the categories of green covering factor used in this study are thought to show no difference with the conditions of no visual stimulation from indoor floor plants. Additionally, Kurazumi et al. [11] found that small indoor floor plants with a green covering factor exceeding $4.67 \%$ placed in a close vicinity on office desktops were oppressive. Therefore, a gaze distance of $2 \mathrm{~m}$ is considered to be similar to a close awareness distance and the extent of the green covering factor stimulates a feeling of oppression, and then shows no improvement of the feeling of discomfort compared to the condition of no visual stimulation from indoor floor plants.

However, a gaze distance of $4.5 \mathrm{~m}$ is considered to be similar to a far awareness distance and conditions with visual stimulation from indoor floor plants showed an improvement in the feeling of discomfort compared to the situation with no visual stimulation. Then, compared to $2 \mathrm{~m}$, a gaze distance of $4.5 \mathrm{~m}$ showed more improvement to the feeling of discomfort. As stated by Kurazumi et al. [11], small indoor floor plants with a green covering factor of less than $4.67 \%$ weaken the feelings of oppression and closeness and it is consistent with the improvements showed in the feeling of discomfort.

An equality test between conditions without visual stimulation from indoor floor plants and gaze distance was conducted using a nonlinear quadratic regression model. The intercept, slope, and quadratic coefficients between a gaze distance $4.5 \mathrm{~m}$ and the condition without visual stimulation from indoor floor plants were each $\mathrm{p}<0.10$ and showed a significant difference. The effect of visual stimulation of indoor floor plants in this study are thought to be influenced by awareness distance and partiality for the indoor floor plants. The variation in general thermal sensation due to higher cognitive processing surmised from the range of results in this study it is considered that it is possible to organically improve the thermal sensation in an inorganic office work space by placing indoor floor plants on the office floor.

\subsection{Visual Stimulation and Effects on the Human Body}

From the relationship between ETF and average skin temperature, similar to the findings of Kurazumi et al. [9] [11], thermal stimulation affects the physiological quantity of average skin temperature, however visual stimulation does not show 
an effect on average skin temperature.

From the relationship between ETF and thermal sensation focusing on decorative plants, for an ETF lower than about $26^{\circ} \mathrm{C}$, conditions with visual stimulation from indoor floor plants alleviated the sensation of being cool compared to the conditions without visual stimulation. This effect was significant for umbellata and monstera that have rounded leaves and low leaf density.

From the relationship between ETF and thermal sensation focusing on gaze distance, for distance to the visual stimulation target of $2 \mathrm{~m}$ and $4.5 \mathrm{~m}$, similar to the determination of a close awareness distance for gaze distance, conditions with visual stimulation from indoor floor plants were shown to alleviate the sensation of being cool, compared to conditions without visual stimulation. Indoor floor plants with a green covering factor accounting for less than $5 \%$ of the visual field are necessary.

From the relationship between ETF and comfort focusing on decorative plants, conditions with visual stimulation from indoor floor plants were shown to improve the feeling of discomfort, compared to conditions without visual stimulation. This effect was significant for pachira, monstera, weeping fig, and umbellate, which have rounded leaves.

From the relationship between ETF and comfort focusing on gaze distance, for a distance to the visual stimulation target of $4.5 \mathrm{~m}$, similar to the determination of a close awareness distance for gaze distance, a green covering factor of less than $5 \%$ was shown to improve the feeling of discomfort.

\section{Conclusions}

For office and living spaces, indoor floor plants are used to effectively bring about relaxation. By quantitatively understanding the variation of thermal sensation on the human body through synergy with visual stimulation, we examined the effectiveness of a summertime air-conditioning set temperature of $28^{\circ} \mathrm{C}$. With a base cooling temperature of $28^{\circ} \mathrm{C}$, experiments were carried out on subjects placed in a mildly uncomfortable temperature range, and we clarified the cognitive stimulation of indoor floor plants on general thermal sensation using the thermal environment evaluation index, ETF [10].

For an ETF below about $26^{\circ} \mathrm{C}$, visual stimulation from indoor floor plants was shown to be effective at alleviating the sensation of being cool. This effect was found to be significant for umbellata and monster, which have rounded leaves and a low leaf density. Gaze distances to the visual stimulation target of $2 \mathrm{~m}$ and $4.5 \mathrm{~m}$, were shown to alleviate the sensation of being cool due to visual stimulation from indoor floor plants. This effect showed that indoor floor plants with a green covering factor accounting for less than $5 \%$ of the visual field are necessary.

Visual stimulation from indoor floor plants was shown to improve the feeling of discomfort. This effect was shown to be significant for pachira, monstera, weeping fig, and umbellata that all have rounded leaves. A gaze distance of $4.5 \mathrm{~m}$ 
to the visual stimulation target showed an improvement in the feeling of discomfort. For this effect, a green covering factor of less than $5 \%$ was shown to be necessary.

When placing indoor floor plants in an office floor space, a gaze distance of up to $4.5 \mathrm{~m}$, which is recognized as being close, is required. Also, decorative plants that have low leaf density and rounded leaves are considered appropriate. This suggests that it is possible to make an amiable, environmentally friendly office by including natural elements from indoor floor plants in the office floor space.

\section{Acknowledgements}

We would like to express our sincerest gratitude to the study subjects who participated in the present study.

\section{References}

[1] Fromm, E. (1964) The Heart of Man: Its Genius for Good and Evil. Harper \& Row Publishers, New York.

[2] Wilson, E.O. (1984) Biophilia. Harvard University Press, Cambridge.

[3] Kellert, S.R. and Wilson, E.O. (1993) The Biophilia Hypothesis. Island Press, Washington DC.

[4] Zajonc, R.B. (1980) Feeling and Thinking: Preferences Need No Inferences. American Psychologist, 35, 151-175. https://doi.org/10.1037/0003-066X.35.2.151

[5] Selhub, E.M. and Logan, A.C. (2012) Your Brain on Nature. John Wiley \&Sons Canada, Toronto.

[6] Ulrich, R.S. (1984) View through a Window May Influence Recovery from Surgery. Science, 224, 420-421. https://doi.org/10.1126/science.6143402

[7] Kurazumi, Y., Matsubara, N., Tsuchikawa, T., Kondo, E., Ishii, J., Fukagawa, K., Ando, Y., Yamato, Y., Tobita, K. and Horikoshi, T. (2011) Psychological Effects of the Environmental Stimuli on Thermal Sense in Outdoor Spaces. Japanese Journal of Biometeorology, 48, 129-144.

[8] Kurazumi, Y., Fukagawa, K., Yamato, Y., Tobita, K., Kondo, E., Tsuchikawa, T., Horikoshi, T. and Matsubara, N. (2011) Enhanced Conduction-Corrected Modified Effective Temperature as the Outdoor Thermal Environment Evaluation Index upon the Human Body. Building and Environment, 46, 12-21.

https://doi.org/10.1016/j.buildenv.2010.06.012

[9] Kurazumi, Y., Fukagawa, K., Kondo, E. and Sakoi, T. (2014) Effects of Visual Stimuli upon Thermal Sense under Air Conditioning in Summer. Journal of Ergonomics, 4, 1-7.

[10] Kurazumi, Y., Tsuchikawa, T., Kondo, E., Horikoshi, T. and Matsubara, N. (2010) Conduction-Corrected Modified Effective Temperature as the Indices of Combined and Separate Effect of Environmental Factors on Sensational Temperature. Energy and Buildings, 42, 441-448. https://doi.org/10.1016/j.enbuild.2009.10.012

[11] Kurazumi, Y., Kondo, E., Fukagawa, K., Hashimoto, R., Nyilas, A., Sakoi, T. and Tsuchikawa, T. (2017) The Influence of Foliage Plants on Psychological and Physiological Responses. Health, 9, 601-621. https://doi.org/10.4236/health.2017.94043

[12] Kurazumi, Y., Tsuchikawa, T., Kondo, E., Yamato, Y., Tobita, K., Fukagawa, K., 
Horikoshi, T. and Matsubara, N. (2009) Validity and Evaluation Method of Combined Thermal Environmental Factors upon the Human Body. Japanese Journal of Biometeorology, 46, 121-137.

[13] World Medical Association (2017) WMA Declaration of Helsinki-Ethical Principles for Medical Research Involving Human Subjects.

https://www.wma.net/policies-post/wma-declaration-of-helsinki-ethical-principlesf or-medical-research-involving-human-subjects/

[14] Hanada, K., Mihira, K. and Ohhata, K. (1981) Studies on the Thermal Resistance of Women's Underweares. Journal of the Japan Research Association for Textile End-Use, 22, 430-437.

[15] Kurazumi, Y., Tsuchikawa, T., Torii, T., Kakutani, K., Matsubara, N. and Horikoshi, T. (2004) Weighting Coefficients for Calculating Mean Skin Temperature When Considering Convective Heat Transfer Areas. Journal of the Human-Environmental System, 7, 19-28. https://doi.org/10.1618/jhes.7.19

[16] Kurazumi, Y., Matsubara, N., Furukawa, N., Fujiwara, M., Ue, A., Ueki, Y., Nagai, H. and Yamamoto, S. (1998) Japanese Weighting Coefficients for Calculating Mean Skin Temperature in Relation to Posture. Japanese Journal of Biometeorology, 35, 121-132.

[17] Kurazumi, Y., Horikoshi, T., Tsuchikawa, T. and Matsubara, N. (1994) The Body Surface Area of Japanese. Japanese Journal of Biometeorology, 31, 5-29.

[18] Kurazumi, Y., Tsuchikawa, T., Matsubara, N. and Horikoshi, T. (2008a) Effect of Posture on the Heat Transfer Areas of the Human Body. Building and Environment, 43, 1555-1565. https://doi.org/10.1016/j.buildenv.2007.09.001

[19] Tsuchikawa, T., Kobayashi, Y., Horikoshi, T., Miwa, E., Kurazumi, Y. and Hirayama, K. (1988) The Effective Radiation Area of the Human Body and Configuration Factors between the Human Body and Rectangular Planes and Measured by the Photographic Method, Measurement for Male Subjects; Four Combinations of Nude or Closed and Standing or Sedentary Postures. Journal of Architecture, Planning and Environmental Engineering, 388, 48-59.

[20] Kurazumi, Y., Tsuchikawa, T., Ishii, J., Fukagawa, K., Yamato, Y. and Matsubara, N. (2008) Radiative and Convective Heat Transfer Coefficients of the Human Body in Natural Convection. Building and Environment, 43, 2142-2153.

https://doi.org/10.1016/j.buildenv.2007.12.012

[21] Hendler, E., Crosbie, R. and Hardy, J.D. (1958) Measurement of Heating of the Skin during Exposure to Infrared Radiation. Journal of Applied Physiology, 12, 177-185. https://doi.org/10.1152/jappl.1958.12.2.177

[22] Kurazumi, Y., Sakoi, T., Tsuchikawa, T., Fukagawa, K., Bolashikov, Z.D. and Horikoshi, T. (2014) Behavioral Thermoregulation Model for Evaluation of Outdoor Thermal Environment. Journal of Ergonomics, 4, 1-14.

https://doi.org/10.4172/2165-7556.1000125

[23] Fukagawa, K., Kurazumi, Y., Yamato, Y., Tobita, K., Hase, H., Han, S., Oishi, H. and Cao, Z. (2010) The Effect of Visual Stimulus on Thermal Comfort, Analysis of the Visual Factor by Experiment. The 7 th International Cost Engineering Council World Congress \& The 14th Pacific Association of Quantity Surveyors Congress, Singapore, 23-27 July 2010, 1-10. 